nerve. The intra-ocular pressure remained normal in spite of provocative tests.

\title{
REPERENCES
}

Steinberg, Theodore-Coloboma of the Optic Nerve. Amer. Jl. of Ophthal., p. 846. August, 1943.

Adler, Francis H.-Bilateral Partial Colobomata of the Optic Nerve. Amer. Jl. - of Ophthai., p. 777. August, 1937.

\section{DEPOSITION OF MERCURY IN THE EYE*}

\author{
BY \\ Professor I. ABRAmowicz \\ MEDICAL ACADEMY OF GDANSK, POLAND
}

RECENTLY. I had the opportunity of observing a peculiar case of hydrargism of the eye after long-continued local use of mercury ointment.

H. O., female, aged 57 years, was first seen on February 5, 1946, because of dark pigmentation of the eyelids of both eyes due to local application of mercury ointment. At the age of 16 she had suffered from "blepharitis"-and from that time on, in fear of a relapse, she continued to employ this remedy nearly every night. The last prescription ran : Hydrarg. praecip. alb. 1,0; Vasel. 15,0. Now she was asking for the removal of the pigmentation which appeared about ten years ago and gives her much trouble because of resemblance to an exaggerated make-up.

The two eyes were in about the same condition. The skin of the eyelids was bluish-grey. The conjunctiva showed moderate hyperaemia. Some loose dark particles were in the conjunctival sac. The cornea and lens, observed under oblique illumination, were quite normal. Ophthalmoscopically the media were perfectly transparent. Visual acuity was normal.

Slit-lamp examination revealed dark pigment granules in the bulbar conjunctiva, especially near the cornea, with preferential distribution around the perivascular lymph vessels. In the periphery of the cornea in the region of Descemet's membrane a discoloration, varying from a greenish-grey to a bluish-grey, was seen. A yellowish-brown lustreless opacity occupied the pupillary area of the lens. Changing of colours was absent. Near the lower pupillary border there was also seen a capsular separation of the senile type of exfoliation. The brownish opacity

* Received for publication, August 12, 1946. 
also covered the bare spaces between the curled up edges of the exfoliation. With higher magnification the discoloration of the cornea and particularly the opacity in the pupillary area had a fine granular appearance. The latter seemed to lie just under the anterior capsule. Any radiating lines extending peripherally from the central capsular deposit were not visible because of rigidity of the pupil. The cortex and the posterior capsule were free.

Anamesis excluded a chalcosis. General physical examination revealed no signs of abnormality. There were no symptoms of mercury poisoning, not considering the bad teeth.

An ointment of 1 per cent. noviform was prescribed. The patient was told the remedy, being harmless, influences as well. The last examination on May 29, 1946, revealed no change in the condition of the eyes.

One may say, therefore, that the condition was caused by local deposition of mercury. The fine equal grains of the deposit seemed to be mostly demonstrable. Vogt in discussing metallic pigmentation produced by heavy metals such as iron, silver and copper, as well as gold and platinum, points out that these grains are generally typical for pigment due to heavy metals. Now one may add mercury to this roll.

I found in the literature a report of lenticular changes due to mercury, which arise industrially (Atkinson, 1943). Atkinson has noted a brownish coloured reflex from the anterior lens surface in workers engaged for a long time in industries in which mercury is used although they may show no other signs of mercury poisoning. The cornea was not involved. Atkinson stated that glass lenses which have been exposed to mercury vapour present a similar brown reflex when examined with the slit-lamp. Atkinson believes the reflex from the lens is caused by deposition of mercury on or in the anterior capsule. The reflex is suggested as an early diagnostic sign of chronic mercurialism. In this connection the above-mentioned case seems to be of some significance.

\section{Summary}

A case of deposition of mercury in the eyelids, the bulbar conjunctiva, the region of Descemet's membrane, and anterior lens capsule after long-continued local applicàtion of mercury ointment is described.

\section{REFERENCES}

VogT, A.-Lehrbuch und Atlas der Spaltlampenmikroskopie, Vol. I, p. 159; Vol. II, p. 663.

Atkinson, W. S.-Amer. Jl. Ophthal., p. 685-687, 1943. 